\title{
Methyl jasmonate induces the apoptosis of human colorectal cancer cells via downregulation of EZH2 expression by microRNA-101
}

\author{
ZHENG PENG and YONG ZHANG \\ Department of General Surgery, PLA General Hospital, PLA Postgraduate School of Medicine, \\ Beijing 100853, P.R. China
}

Received June 3, 2015; Accepted June 20, 2016

DOI: $10.3892 / \mathrm{mmr} .2016 .6061$

\begin{abstract}
Methyl jasmonate is found universally in the plant kingdom and functions to regulate plant growth and development, as well as in stress responses through signal transduction pathways. The present study aimed to investigate the anticancer effect of methyl jasmonate on SW620 human colorectal cancer cells and its potential underlying mechanism. SW620 cells were treated with $0,0.5,0.75,1.5$ and $2.0 \mathrm{mM}$ methyl jasmonate for 12, 24 and $48 \mathrm{~h}$. Methyl jasmonate was shown to be able to inhibit cell growth and induce apoptosis of SW620 cells in a concentration and time-dependent manner, whilst promoting an increase in caspase- 3 protein expression. Compared with control, the anticancer effect of methyl jasmonate inhibited Enhancer of zeste homolog 2 (EZH2) protein expression and activated microRNA (miR)-101 expression in SW620 cells. However, knockdown of miR-101 suppresses methyl jasmonate-induced cell growth inhibition, activation of caspase-3 expression and inhibition of EZH2 expression in SW620 cells. These results demonstrate that methyl jasmonate induced the apoptosis of human colorectal cancer cells via downregulation of EZH2 expression by miR-101.
\end{abstract}

\section{Introduction}

Colorectal cancer is one of the most common types of malignant tumor, with the third highest mortality rate of all cancers (1). Statistics showed that in 2008, there were nearly 1 million new cases of colorectal cancer worldwide and approximately 500,000-related fatalities (2). In recent years, with social and economic development, changes of the dietary patterns, aging of the population and rapid development

Correspondence to: DrZheng Peng,Department of General Surgery, PLA General Hospital, PLA Postgraduate School of Medicine, 28 Fu-Xing Road, Beijing 100853, P.R. China

E-mail: ppzhengpeng@yeah.net

Key words: methyl jasmonate, human colorectal cancer, Enhancer of zeste homolog 2, microRNA-101 of endoscopic techniques, the diagnostic rate of colorectal cancer in China has increased, and become a serious health problem (3). Compared with 1990s and 1970s, the morbidity of colorectal cancer in China in urban areas was increased by $32.0 \%$, while that in rural areas was increased by $8.5 \%$ (4). Furthermore, it has become the most common type of malignant cancer in China.

Occurrence and progression of tumors is an evolutionary process with various factors and steps in which gene expression abnormality is essential (5). With an increasing number of studies on the pathogenic mechanisms of colorectal cancer, there has been a focus on molecular markers that are vital in early diagnosis, clinical stages, individual-based treatment, targeting tumors and prognosis monitoring. The first identification of a microRNA (miRNA) molecule was lin-4 in Caenorhabditis elegans (6). Thus far, nearly 1,500 miRNA sequences have been determined (6). miRNAs are important in tumor occurrence and progression (7). At present, studies of the correlation between certain miRNAs and cancer have attracted great attention. Numerous studies provided new ideas for tumor treatment.

JA (jasmonic acid) is a type of plant hormone, whose methyl derivative is methyl jasmonate. Methyl jasmonate was initially obtained by separation from jasmine and Tunisian rosemary oils (8), however, it is now known to exist universally in plants to stimulate the expression of plant defence genes and their chemical defence. Studies on methyl jasmonate were previously restricted to botany and it was demonstrated to be involved in accelerating organic senescence, inducing fruit ripening and response of plant diseases and insect pests (9). However, it has also been reported that methyl jasmonate could induce cell differentiation of myelogenous leukemia and inhibit its proliferation (10). In addition, methyl jasmonate could induce differentiation and apoptosis of lymphocytic leukemia cells but did not damage normal lymphocytes $(10,11)$. The present study demonstrated the anticancer effect of methyl jasmonate-induced apoptosis of human colorectal cancer. Furthermore, the anticancer effect of methyl jasmonate on human colorectal cancer was shown to occur via downregulation of EZH2 expression by miR-101. Data may suggest that methyl jasmonate may be developed as a novel drug for the treatment of colorectal cancer. 


\section{Materials and methods}

Reagents. RPMI-1640 was purchased from PAN Biotech (Aidenbach, Germany). Fetal bovine serum (FBS) was purchased from HyClone (Logan, UT, USA). Cell Counting Kit-8 assay (CCK-8) was obtained from Hangzhou Evergreen Company (Hangzhou, China). Fluorescein isothiocyanate-conjugated Annexin V (Annexin V-FITC)/propidium iodide (PI) was obtained from BD Pharmingen (San Diego, CA, USA). Bicinchoninic acid (BCA) Protein Assay kit and Lipofectamine 2000 were purchased from Thermo Fisher Scientific Inc. (Waltham, MA, USA). TRIzol reagent was from Invitrogen Thermo Fisher Scientific Inc. cDNA Synthesis kit was purchased from Takara Biotechnology Inc. (Dalian, China).

Cell culture. SW620 human colorectal cancer cells were purchased from the Cell Bank of the Chinese Academy of Sciences (Shanghai, China) and cultured with RPMI-1640 and $10 \% \mathrm{FBS}$ at $37^{\circ} \mathrm{C}$ in an atmosphere of $5 \% \mathrm{CO}_{2}$.

In vitro cell viability assay. SW620 cells were plated at a density of $1 \times 10^{4}$ cells per well in 96-well plates. Briefly, after a 12,24 or $48 \mathrm{~h}$ drug treatment with control, $0.5,0.75,1.5$ or $2.0 \mathrm{mM}$ methyl jasmonate (structure shown in Fig. 1), SW620 cells were incubated with $10 \mu \mathrm{l}$ CCK-8 for additional $2 \mathrm{~h}$ at $37^{\circ} \mathrm{C}$ in the dark. Absorbance of SW620 cells was measured on an Opsys MR spectrophotometer (DYNEX Technologies, Denkendorf, Germany) at $450 \mathrm{~nm}$.

Apoptotic cells. SW620 cells were plated at a density of $1-2 \times 10^{6}$ cells per well in 96-well plates. Briefly, after a $24 \mathrm{~h}$ drug treatment with control, $0.5,0.75$ or $1.5 \mathrm{mM}$ methyl jasmonate, SW620 cells were incubated with Annexin V-FITC and PI for $30 \mathrm{~min}$ in the dark. Apoptotic cells were analyzed by flow cytometry (FACScan, Becton Dickinson, Mountain View, CA, USA).

Western blot analysis. SW620 cells were plated at a density of $1-2 \times 10^{6}$ cells per well in 96 -well plates. Briefly, after a $24 \mathrm{~h}$ drug treatment with control, $0.5,0.75$ or $1.5 \mathrm{mM}$ methyl jasmonate, SW620 cells were incubated with $1 \mathrm{X}$ cell lysis buffer (Promega Corporation, Madison, WI, USA). Protein concentration was measured using a BCA Protein Assay kit. Equal quantities of total proteins $(80 \mu \mathrm{g})$ were boiled, separated by sodium dodecyl sulfate-polyacrylamide gel electrophoresis and blotted onto polyvinylidene fluoride membranes (Millipore, Darmstadt, Germany). Following alternative immunoblot analysis with monoclonal mouse anti-human caspase-3 (1:2,000; Santa Cruz Biotechnology, Inc., Dallas, TX, USA; cat. no. sc-56050), monoclonal mouse anti-human EZH2 (1:1,000; Cell Signaling Technology, Inc., Danvers, MA, USA; cat. no. 3147) and monoclonal mouse anti-human $\beta$-actin (1:5,000; Santa Cruz Biotechnology Inc.; cat. no. sc-130300). Immunoreactive bands were incubated using the specific goat anti-rabbit horseradish peroxidase-conjugated secondary antibody (1:5,000; Beyotime Institute of Biotechnology, Haimen, China; cat. no. A0216) and the enhanced chemiluminescence system (Amersham Biosciences, Piscataway, NJ, USA). Band intensities were

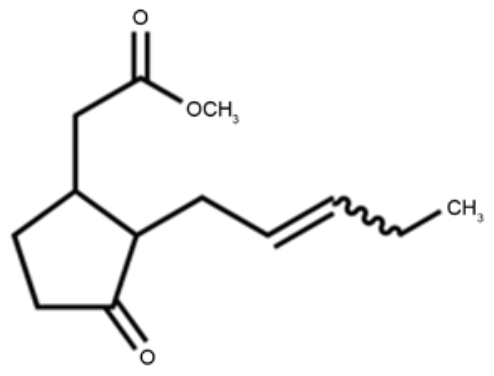

Figure 1. Chemical structure of methyl jasmonate.

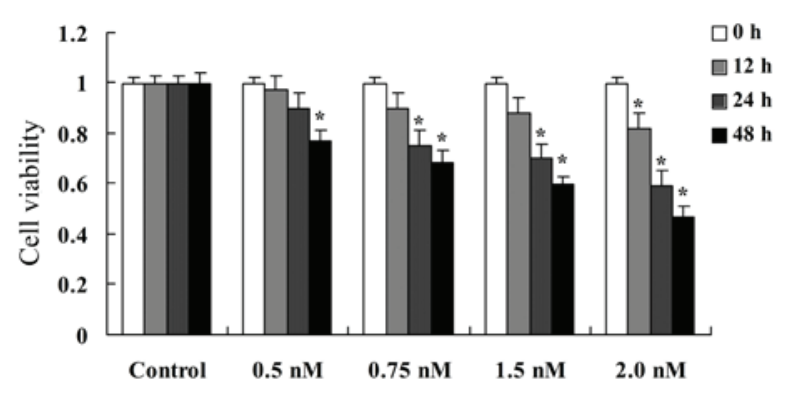

Figure 2. Methyl jasmonate induced growth inhibition of human colorectal cancer cells. ${ }^{*} \mathrm{P}<0.01$ compared with the control group.

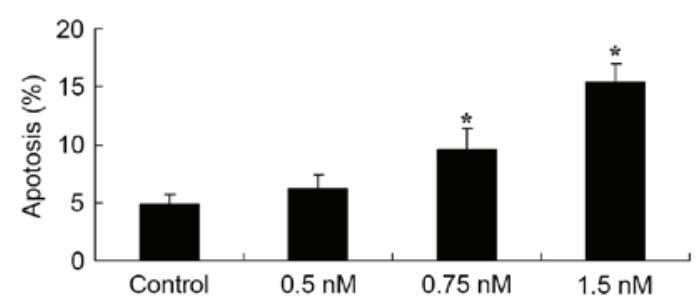

Figure 3. Methyl jasmonate induced apoptosis of human colorectal cancer cells. ${ }^{*} \mathrm{P}<0.01$ compared with the control group.

quantified using the Image J 2.1.4.7 software (National Institutes of Health, Bethesda, MD, USA)

Reverse transcription-quantitative polymerase chain reaction $(R T-q P C R)$ analysis. SW620 cells were plated at a density of $1-2 \times 10^{6}$ cells per well in 96 -well plates. Briefly, after a $24 \mathrm{~h}$ drug treatment with control, $0.5,0.75$ or $1.5 \mathrm{mM}$ methyl jasmonate, SW620 cells were incubated with the TRIzol reagent to isolate Total RNA. The Transcriptor First Strand cDNA Synthesis kit (Takara Biotechnology Inc., Dalian, China) was used to transcribe cDNA from 1-2 $\mu \mathrm{g}$ total RNA. qPCR was performed with $500 \mathrm{ng}-1 \mu \mathrm{g}$ cDNA using Applied Biosystems 7,700 HT Real-Time PCR System (Thermo Fisher Scientific, Inc.). PCR reactions were performed under the following conditions: 40 cycles at $95^{\circ} \mathrm{C}$ for $15 \mathrm{sec}$, at $60^{\circ} \mathrm{C}$ for $40 \mathrm{sec}$ and $72^{\circ} \mathrm{C}$ for $30 \mathrm{sec}$ analysis was performed at the end. The PCR primers were as follows: miR-101: 5'-TGCTGT ACAGTACTGTGATACGAGTTTTGGCCACTGACTGAC TTCAGTTAACAGTACTGTA-3' and 5'-CCTGTACAGTAC TGTTAACTGAAGTCAGTCAGTGGCCAAAACTTCAGT TATCACAGTACTGTAC-3'; U6: 5'-CTCGCTTCGGCA GCACATA-3' and 5'-AACGCTTCACGAATTTGCGT-3'. 
A

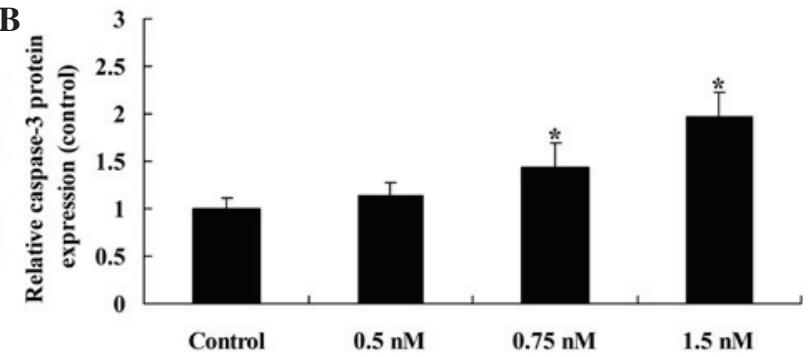

Figure 4. Methyl jasmonate induced activation of caspase-3 expression. (A) Methyl jasmonate induced activation of caspase-3 protein expression by western blotting assays and (B) statistical analysis of caspase-3 protein expression. ${ }^{*} \mathrm{P}<0.01$ compared with the control group.

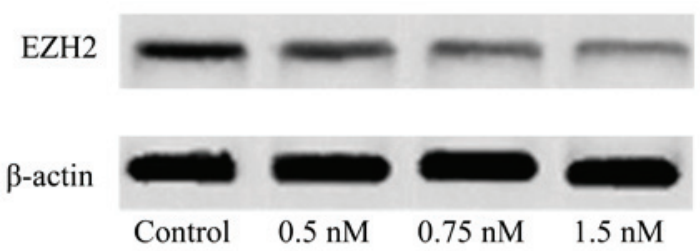

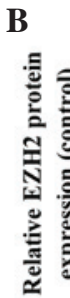

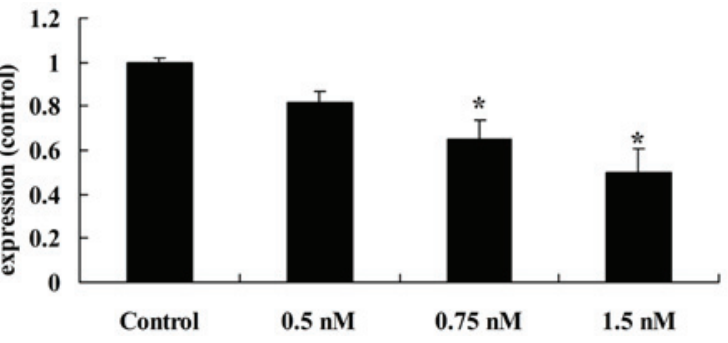

Figure 5. Methyl jasmonate induced the inhibition of EZH2 expression. (A) Methyl jasmonate induced activation of EZH2 protein expression by western blotting assays and (B) statistical analysis of EZH2 protein expression. ${ }^{*} \mathrm{P}<0.01$ compared with the control group. EZH2, Enhancer of zeste homolog 2.

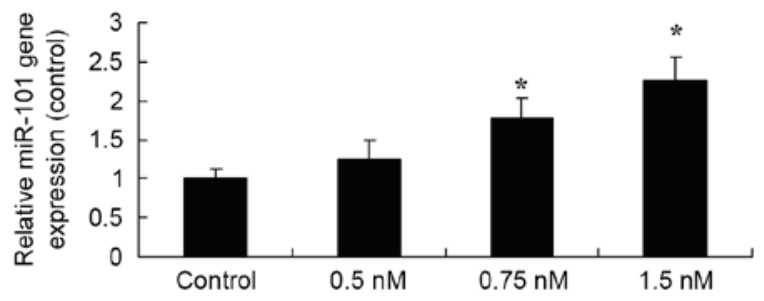

Figure 6. Methyl jasmonate induced upregulation of miR-101 expression. ${ }^{*} \mathrm{P}<0.01$ compared with the control group. miR, microRNA.

The relative expression levels were calculated using the $2^{-\Delta \Delta \mathrm{Cq}}$ method (12)

Pre-miR-101 construct and stable transfection. Pre-miR-101-EGFP (5'-TACAGTACTGTGATAACTGAA-3') and negative control-EGFP were structured (GenePharma Co., Ltd., Shanghai, China) and were transfected into SW620 cells using Lipofectamine 2000.

Statistical analysis. Statistical analysis was performed using SPSS 17.0 software (SPSS Inc., Chicago, IL, USA). Continuous variables were expressed as the mean \pm standard error of the mean. Statistical comparison between groups was conducted using one way analysis of variance followed by the Tukey-Kramer method. $\mathrm{P}<0.05$ was considered to indicate a statistically significant difference.

\section{Results}

Methyl jasmonate induces growth inhibition of human colorectal cancer cells. In order to confirm the anticancer effect of methyl jasmonate on cell growth of human colorectal cancer cells, the cell viability of SW620 was determined using
CCK-8. The results indicated that $0.5,0.75,1.5$ and $2.0 \mathrm{nM}$ methyl jasmonate significantly inhibited cell viability of SW620 cells in a dose- and time-dependent manner, when compared with the untreated control $(\mathrm{P}=0.0094, \mathrm{P}=0.0082$, $\mathrm{P}=0.0042$ and $\mathrm{P}=0.0028$, respectively; Fig. 2). This suggests that methyl jasmonate can potentiate the inhibitory effect on the growth of colorectal cancer cells.

Methyl jasmonate induces apoptosis of human colorectal cancer cells. To confirm that cell apoptosis was involved in methyl jasmonate-induced effect on cell growth of human colorectal cancer cells, cell apoptosis in SW620 cells was assessed using (FITC)-conjugated Annexin V (Annexin V-FITC)/propidium iodide (PI) kit. SW620 cell staining indicated that the administration of 0.75 and $1.5 \mathrm{mM}$ methyl jasmonate increased cell apoptosis of SW620 cells in a dose-dependent manner, when compared with the untreated control ( $\mathrm{P}=0.0018$ and $\mathrm{P}=0.0008$, Fig. 3).

Methyl jasmonate induces activation of caspase-3 expression. The protein expression of caspase- 3 was then examined by western blot analysis, the critical executioner of apoptosis. The results indicated that 0.75 and $2.0 \mathrm{mM}$ methyl jasmonate induced the production of caspase- 3 in a dose-dependent manner in SW620 cells, when compared with the untreated control ( $\mathrm{P}=0.0034$ and $\mathrm{P}=0.0018$, Fig. 4).

Methyl jasmonate induces inhibition of EZH2 expression. To confirm the effect of methyl jasmonate on EZH2 protein expression of SW620 cells, EZH2 protein expression was measured using western blot analysis. It was demonstrated that 0.75 and $2.0 \mathrm{mM}$ methyl jasmonate suppressed the EZH2 protein expression of SW620 cells, when compared with the untreated control $(\mathrm{P}=0.0034$ and $\mathrm{P}=0.0018$, Fig. 5). 
A

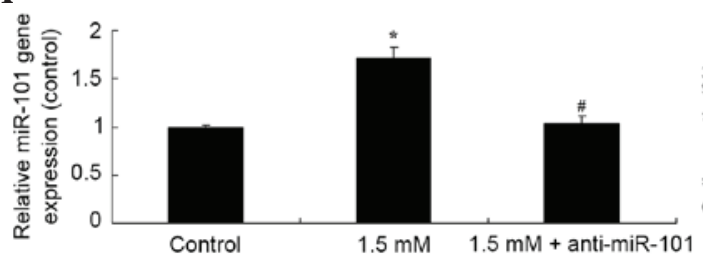

B

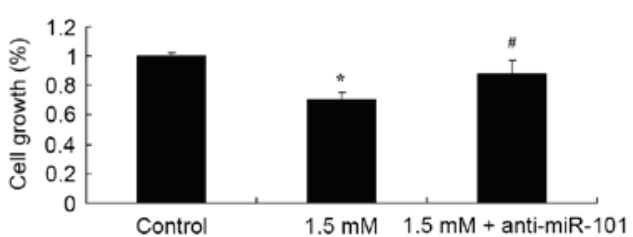

Figure 7. Knockdown of miR-101 suppresses methyl jasmonate-induced growth inhibition of human colorectal cancer cells. (A) miR-101 expression and (B) growth inhibition of human colorectal cancer cells. ${ }^{*} \mathrm{P}<0.01$ compared with the control group; ${ }^{\#} \mathrm{P}<0.01$ compared with the $1.5 \mathrm{mM}$ methyl jasmonate group. miR, microRNA.

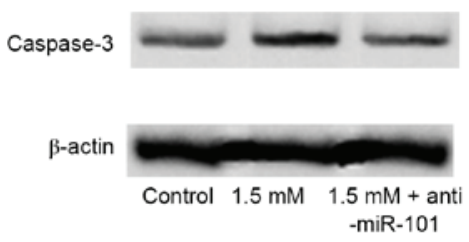

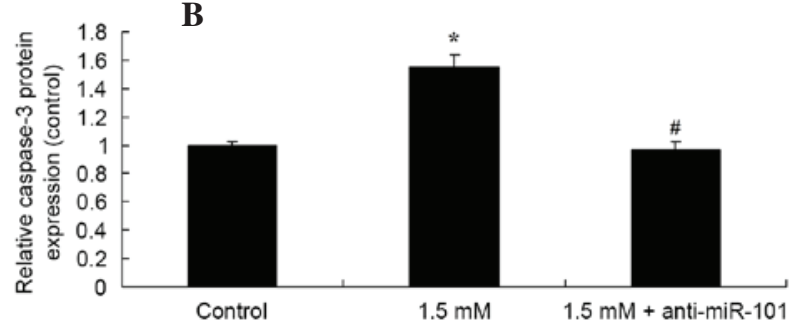

Figure 8. Knockdown of miR-101 suppresses methyl jasmonate-induced activation of caspase-3 expression. (A) Knockdown of miR-101 suppresses methyl jasmonate-induced activation of caspase- 3 protein expression by western blotting assays and (B) statistical analysis of caspase- 3 protein expression. * $\mathrm{P}<0.01$ compared with the control group; ${ }^{\#} \mathrm{P}<0.01$ compared with the $1.5 \mathrm{mM}$ methyl jasmonate group. miR, microRNA.

$\mathbf{A}$

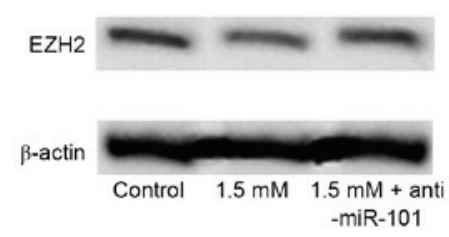

B

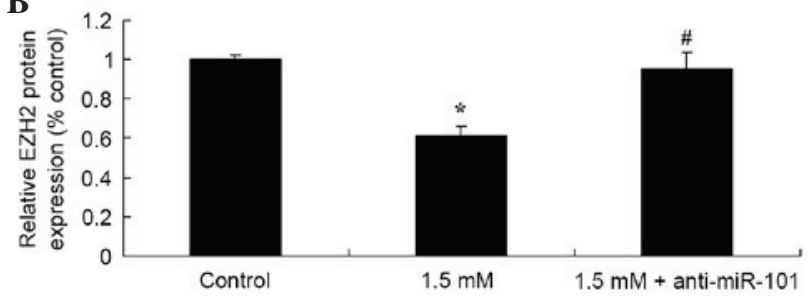

Figure 9. Knockdown of miR-101 suppresses methyl jasmonate-induced inhibition of EZH2 expression. (A) Knockdown of miR-101 suppresses methyl jasmonate-induced activation of EZH2 protein expression by western blotting assays and (B) statistical analysis of EZH2 protein expression. ${ }^{*} \mathrm{P}<0.01$ compared with the control group; ${ }^{\prime} \mathrm{P}<0.01$ compared with the $1.5 \mathrm{mM}$ methyl jasmonate group. miR, microRNA; EZH2, Enhancer of zeste homolog 2.

Methyl jasmonate induces upregulation of miR-101 expression . In order to ascertain the effect of methyl jasmonate on mediating miR-101 expression, qPCR was conducted to analyze gene expression Data showed that 0.75 and $2.0 \mathrm{mM}$ methyl jasmonate upregulated the miR-101 expression in SW620 cells $(\mathrm{P}=0.0088$ and $\mathrm{P}=0.0042$, Fig. 6).

Knockdown of miR-101 suppresses methyl jasmonate-induced growth inhibition of human colorectal cancer cells. The mechanisms underlying the effect of methyl jasmonate on the reduction of cell viability by detecting the expression of miR-101 were further investigated. The data showed that knockdown of miR-101 suppresses the miR-101 expression in SW620 cells and $1.5 \mathrm{mM}$ methyl jasmonate-induced miR-101 expression (Fig. 7A). In addition, knockdown of miR-101 reversed the $1.5 \mathrm{mM}$ methyl jasmonate-induced suppression of SW620 cell growth ( $\mathrm{P}=0.0042$, Fig. 7B).

Knockdown of miR-101 suppresses methyl jasmonate-induced activation of caspase-3 expression. The mechanisms underlying the effects of methyl jasmonate on caspase- 3 expression and the induction of apoptosis of SW620 cells were investigated.
Data showed that knockdown of miR-101 reversed the $1.5 \mathrm{mM}$ methyl jasmonate-induced increase in caspase- 3 protein expression in SW620 cells ( $\mathrm{P}=0.0036$, Fig. 8).

Knockdown of miR-101 suppresses methyl jasmonate-induced inhibition of EZH2 expression. The mechanisms underlying the effect of methyl jasmonate on the EZH2 expression of SW620 cells. Results demonstrated that knockdown of miR-101 reversed the $1.5 \mathrm{mM}$ methyl jasmonate-induced decrease in $\mathrm{EZH} 2$ protein expression in $\mathrm{SW} 620$ cells $(\mathrm{P}=0.0031$ and $\mathrm{P}=0.0004$, Fig. 9).

\section{Discussion}

Colorectal cancer is one of most common types of malignant tumor, with the third highest cancer-related mortality rate (1). However, the pathogenesis of colorectal cancer needs to be fully determined and difficulties remain in diagnosis and treatment. Consequently, morbidity and mortality rates are high. By far, the most effective treatment method is the combination of radical surgery and chemotherapy. Five-year survival rates of patients with local tumors are $93 \%$ (13). However, nearly 
$50 \%$ patients have metastasis at initial diagnosis (13). In addition, more than one third of patients with local tumors relapse following surgery (13). In this study, methyl jasmonate induced growth inhibition, apoptosis and caspase-3 protein expression in SW620 cells. It was reported that methyl jasmonate reduces growth of cervical cancer cells (14), human prostate adenocarcinoma cells (15) and human lung adenocarcinoma cells (16).

The EZH2 human gene was identified in 1996 (17). $\mathrm{EZH} 2$ protein is evidently upregulated in metastatic prostate cancer and breast cancer (18). As a transcriptional repressor protein, EZH2 inhibits transcription of numerous genes and leads to increased tumor invasion and metastasis $(19,20)$. Among inhibited genes, the majority inhibit development and progression of tumors, which increases the expression of metastasis-promoting genes (21). Expression of EZH2 protein in colorectal cancer tissues is higher than that in normal colorectal tissues (22). In addition, it was suggested that as an oncogene, $\mathrm{EZH} 2$ is closely associated with the occurrence and progression of liver cancer (23). Methyl jasmonate was also shown to suppress EZH2 protein expression in SW620 cells. Wang et al (24) demonstrated that methyl jasmonate sensitizes gembogic acid-induced apoptosis of human bladder cancer cells via downregulation of EZH2 expression by miR-101.

Increasing evidence suggests that miRNA is crucial in the carcinogenesis and progression of tumors. A large number of miRNAs have been demonstrated to be upregulated or downregulated in various types of tumor (25). Among occurrence of various tumors, part of miRNA has the function of tumor-inhibiting factors while part of it has the function of tumor promoters. miRNA-101 is important in malignant tumors and its abnormal expression has been confirmed in a number of studies (26-28). A previous study demonstrated that miR-101 is associated with the metastasis of cancer and the inhibition of miR-101 can facilitate metastasis of colorectal cancer (29). In this study, miR-101 expression was demonstrated to be upregulated in SW620 cells. Knockdown of miR-101 was shown to suppress the anticancer effect of methyl jasmonate-induced growth inhibition, caspase- 3 protein expression, and inhibition of EZH2 expression in SW620 cells. Wang et al (24) expounded that methyl jasmonate sensitizes gembogic acid-induced apoptosis of human bladder cancer cells via downregulation of EZH2 expression through miR-101.

In conclusion, the present study demonstrates that the anticancer effect of methyl jasmonate suppresses cell growth and induces apoptosis of SW620 human colorectal cancer cells and increases caspase- 3 expression. These results indicate that its anticancer effects occur via suppression of the EZH2 pathway and activation of miR-101 expression in SW620 cells.

\section{References}

1. Negri FV, Musolino A, Naldi N, Bortesi B, Missale G,Laccabue D, Zerbini A, Camisa R, Chernyschova N, Bisagni G, et al: Role of immunoglobulin $\mathrm{G}$ fragment $\mathrm{C}$ receptor polymorphism-mediated antibody-dependant cellular cytotoxicity in colorectal cancer treated with cetuximab therapy. Pharmacogenomics J 14: 14-19, 2014.

2. Hong YS, Nam BH, Kim KP, Kim JE, Park SJ, Park YS, Park JO, Kim SY, Kim TY, Kim JH, et al: Oxaliplatin, fluorouracil, and leucovorin versus fluorouracil and leucovorin as adjuvant chemotherapy for locally advanced rectal cancer after preoperative chemoradiotherapy (ADORE): An open-label, multicentre, phase 2, randomised controlled trial. Lancet Oncol 15: 1245-1253, 2014.
3. Zhang RX, Wu XJ, Lu SX, Pan ZZ, Wan DS and Chen G: The effect of COX-2 inhibitor on capecitabine-induced hand-foot syndrome in patients with stage II/III colorectal cancer: A phase II randomized prospective study. J Cancer Res Clin Oncol 137: 953-957, 2011.

4. Weir HK, Thun MJ, Hankey BF, Ries LA, Howe HL, Wingo PA, Jemal A, Ward E, Anderson RN and Edwards BK: Annual report to the nation on the status of cancer, 1975-2000, featuring the uses of surveillance data for cancer prevention and control. J Natl Cancer Inst 95: 1276-1299, 2003.

5. Garzon R, Calin GA and Croce CM: MicroRNAs in cancer. Annu Rev Med 60: 167-179, 2009.

6. Ogata-Kawata H, Izumiya M, Kurioka D, Honma Y, Yamada Y, Furuta K, Gunji T, Ohta H, Okamoto H, Sonoda H, et al: Circulating exosomal microRNAs as biomarkers of colon cancer. PLoS One 9: e92921, 2014.

7. Nouraee N and Calin GA: MicroRNAs as cancer biomarkers. Microrna 2: 102-117, 2013.

8. Cohen S and Flescher E: Methyl jasmonate: A plant stress hormone as an anti-cancer drug. Phytochemistry 70: 1600-1609, 2009.

9. Cheong JJ and Choi YD: Methyl jasmonate as a vital substance in plants. Trends Genet 19: 409-413, 2003.

10. Tsumura H, Akimoto M, Kiyota H, Ishii Y, Ishikura $H$ and Honma Y: Gene expression profiles in differentiating leukemia cells induced by methyl jasmonate are similar to those of cytokinins and methyl jasmonate analogs induce the differentiation of human leukemia cells in primary culture. Leukemia 23: 753-760, 2009

11. Ishii Y, Kiyota H, Sakai S and Honma Y: Induction of differentiation of human myeloid leukemia cells by jasmonates, plant hormones. Leukemia 18: 1413-1419, 2004.

12. Pu Z, Zhang X, Chen Q, Yuan X and Xie H: Establishment of an expression platform of OATP1B1 388GG and 521CC genetic polymorphism and the therapeutic effect of tamoxifen in MCF-7 cells. Oncol Rep 33: 2420-2428, 2015.

13. Mihajlovic M, Vlajkovic S, Jovanovic P and Stefanovic V: Primary mucosal melanomas: A comprehensive review. Int $\mathrm{J}$ Clin Exp Pathol 5: 739-753, 2012.

14. Milrot E, Jackman A, Kniazhanski T, Gonen P, Flescher E and Sherman L: Methyl jasmonate reduces the survival of cervical cancer cells and downregulates HPV E6 and E7, and survivin. Cancer Lett 319: 31-38, 2012.

15. Ezekwudo D, Shashidharamurthy R, Devineni D, Bozeman E, Palaniappan R and Selvaraj P: Inhibition of expression of anti-apoptotic protein $\mathrm{Bcl}-2$ and induction of cell death in radioresistant human prostate adenocarcinoma cell line (PC-3) by methyl jasmonate. Cancer Lett 270: 277-285, 2008.

16. Kim JH, Lee SY, Oh SY, Han SI, Park HG, Yoo MA and Kang HS: Methyl jasmonate induces apoptosis through induction of Bax/Bcl-XS and activation of caspase- 3 via ROS production in A549 cells. Oncol Rep 12: 1233-1238, 2004.

17. Gharpure KM, Chu KS, Bowerman CJ, Miyake T, Pradeep S, Mangala SL, Han HD, Rupaimoole R, Armaiz-Pena GN, Rahhal TB, et al: Metronomic docetaxel in PRINT nanoparticles and EZH2 silencing have synergistic antitumor effect in ovarian cancer. Mol Cancer Ther 13: 1750-1757, 2014.

18. Deb G, Thakur VS and Gupta S: Multifaceted role of EZH2 in breast and prostate tumorigenesis: Epigenetics and beyond. Epigenetics 8: 464-476, 2013

19. Tsang DP and Cheng AS: Epigenetic regulation of signaling pathways in cancer: Role of the histone methyltransferase EZH2. J Gastroenterol Hepatol 26: 19-27, 2011.

20. Ferraro A, Boni T and Pintzas A: EZH2 regulates cofilin activity and colon cancer cell migration by targeting ITGA2 gene. PLoS One 9: e115276, 2014.

21. Bryant RJ, Cross NA, Eaton CL, Hamdy FC and Cunliffe VT: EZH2 promotes proliferation and invasiveness of prostate cancer cells. Prostate 67: 547-556, 2007.

22. Wang J, Ma ZB, Li K and Guo GH: Association between EZH2 polymorphisms and colorectal cancer risk in Han Chinese population. Med Oncol 31: 874, 2014.

23. Cheng AS, Lau SS, Chen Y, Kondo Y, Li MS, Feng H, Ching AK, Cheung KF, Wong HK, Tong JH, et al: EZH2-mediated concordant repression of Wnt antagonists promotes $\beta$-catenin-dependent hepatocarcinogenesis. Cancer Res 71: 4028-4039, 2011.

24. Wang Y, Xiang W, Wang M, Huang T, Xiao X, Wang L, Tao D, Dong L, Zeng F and Jiang G: Methyl jasmonate sensitizes human bladder cancer cells to gambogic acid-induced apoptosis through down-regulation of EZH2 expression by miR-101. Br J Pharmacol 171: 618-635, 2014. 
25. Slaby O, Svoboda M, Michalek J and Vyzula R: MicroRNAs in colorectal cancer: Translation of molecular biology into clinical application. Mol Cancer 8: 102, 2009.

26. Mirnezami AH, Pickard K, Zhang L, Primrose JN and Packham G: MicroRNAs: Key players in carcinogenesis and novel therapeutic targets. Eur J Surg Oncol 35: 339-347, 2009.

27. Zheng HB, Zheng XG and Liu BP: miRNA-101 inhibits ovarian cancer cells proliferation and invasion by down-regulating expression of SOCS-2. Int J Clin Exp Med 8: 20263-20270, 2015.
28. Jiang W, Gu W, Qiu R, He S, Shen C, Wu Y, Zhang J, Zhou J, Guo Y, Wan D, et al: miRNA-101 suppresses epithelial-to-mesenchymal transition by targeting HMGA2 in pancreatic cancer cells. Anticancer Agents Med Chem 16: 432-439, 2016.

29. Strillacci A, Valerii MC, Sansone P, Caggiano C, Sgromo A, Vittori L, Fiorentino M, Poggioli G, Rizzello F, Campieri M and Spisni E: Loss of miR-101 expression promotes Wnt $/ \beta$-catenin signalling pathway activation and malignancy in colon cancer cells. J Pathol 229: 379-389, 2013. 